\title{
Anesthetic Considerations on Adrenal Gland Surgery
}

\author{
Rudin Domi ${ }^{\mathrm{a}, \mathrm{d}}$, Hektor Sula ${ }^{\mathrm{a}}$, Myzafer Kaci ${ }^{\mathrm{b}}$, Sokol Paparisto ${ }^{\mathrm{b}}$, Artan Bodecic ${ }^{\mathrm{c}}$, Astrit Xhemali ${ }^{\mathrm{b}}$
}

\begin{abstract}
Adrenal gland surgery needs a multidisciplinary team including endocrinologist, radiologist, anesthesiologist, and surgeon. The indications for adrenal gland surgery include hormonal secreting and non-hormonal secreting tumors. Adrenal hormonal secreting tumors present to the anesthesiologist unique challenges requiring good preoperative evaluation, perioperative hemodynamic control, corrections of all electrolytes and metabolic abnormalities, a detailed and careful anesthetic strategy, overall knowledge about the specific diseases, control and maintaining of postoperative adrenal function, and finally a good collaboration with other involved colleagues. This review will focus on the endocrine issues, as well as on the above-mentioned aspects of anesthetic management during hormone secreting adrenal gland tumor resection.
\end{abstract}

Keywords: General anesthesia; Adrenal gland; Preoperative evaluation

\section{Introduction}

The adrenal cortex produces three types of hormones: glucocorticoids (cortisol), mineralocorticoids (aldosterone and 11-deoxycorticosterone), and androgens. Cushing's syndrome caused either by the overproduction of cortisol by the adrenal cortex or exogenous glucocorticoid therapy, results in a syndrome characterized by truncal obesity, hypertension, hy-

Manuscript accepted for publication September 04, 2014

aDepartment of Anesthesiology and Intensive Care Medicine, "Mother Teresa" University Hospital Center, Tirana, Albania

bDepartment of General Surgery, "Mother Teresa" University Hospital Center, Tirana, Albania

'Department of Oncologic Surgery, "Mother Teresa" University Hospital Center, Tirana, Albania

${ }^{\mathrm{d} C}$ Corresponding Author: Rudin Domi, Department of Anesthesiology and Intensive Care Medicine, "Mother Teresa" University Hospital Center, Tirana, Albania. Email: rdomi73@yahoo.it

doi: http://dx.doi.org/10.14740/jocmr1960w perglycemia, increased intravascular fluid volume, hypokalemia, abdominal striae, osteoporosis, and muscle weakness. Aldosterone is a major regulator of extracellular volume and potassium homeostasis. Hypersecretion (Conn's syndrome) of the major adrenal mineralocorticoid aldosterone increases the renal tubular exchange of sodium for potassium and hydrogen ions, leading to hypertension, hypokalemic alkalosis, skeletal muscle weakness, and fatigue. Adrenal medulla produces epinephrine and norepinephrine. Pheochromocytoma is a neuroendocrine tumor arising from chromaffin cells in the adrenal medulla causing less than $0.1 \%$ of all cases of hypertension. Usually, tumors are benign but in $10 \%$ of the cases they may be malignant. These tumors may secrete the catecholamine (dopamine, norepinephrine, and epinephrine). Indications for adrenalectomy include primary or secondary (metastasis) tumors of adrenal glands and of course hormonal secretion diseases like Cushing (glucocorticoid excess), Conn (mineral corticoid excess), and pheochromocytoma (catecholamine excess). This review is focused on anesthetic management of these diseases.

\section{Conn's Syndrome}

\section{General considerations}

Hyperaldosteronism is characterized by an excess of aldosterone. Hyperaldosteronism can be divided in primary and secondary one. The secondary hyperaldosteronism may be due to severe liver diseases, nephritic syndrome, and cardiac failure. The primary form (Conn's syndrome) presents the excess of aldosterone due to an adrenal gland disease. In the majority of cases $(60 \%)$ a unilateral adenoma may be verified, whereas bilateral adrenal hyperplasia is faced in $30 \%$ of cases. It is more common in females than males $[1,2]$, and is the cause of $5-13 \%$ of secondary hypertension and less than $1 \%$ of essential one [2]. As aforementioned hyperaldosteronism can be two forms: primary and secondary hyperaldosteronism. Primary hyperaldosteronism is known as Conn's syndrome resulting from unilateral or bilateral adrenal gland tumors [35]. Secondary hyperaldosteronism is due to increased levels of renin, inducing the renin-aldosterone axis activitation. These pathophysiologic changes are usually present in severe cardiac failure, nephritic syndrome, and advanced liver disease. 
Table 1. Conn's Syndrome and Anesthetic Management

\begin{tabular}{|ll|}
\hline Conn's syndrome & Treatment \\
\hline $\begin{array}{l}\text { Preoperative period } \\
\text { Preoperative hypokalemia }\end{array}$ & $\begin{array}{l}\text { Begin spironolactone, supplement kalium } \\
\text { Continue preoperative antihypertensive drugs }\end{array}$ \\
$\begin{array}{l}\text { Hypertension } \\
\text { Premedication }\end{array}$ & Adequate sedation \\
\hline $\begin{array}{l}\text { Intraoperative period } \\
\text { Metabolic alkalosis }\end{array}$ & $\begin{array}{l}\text { Avoid hyperventilation } \\
\text { Hemodynamic state }\end{array}$ \\
$\begin{array}{l}\text { Potassium level, gas analysis } \\
\text { Strict hemodynamic control }\end{array}$ & Frequent measures of acid-base status and potassium blood level \\
\hline
\end{tabular}

The clinical features include systemic hypertension, metabolic alkalosis, hypokalemia, increased urinary excretion of potassium, hypernatremia, fatigue, muscle cramps, and skeletal muscle weakness. Systemic hypertension (often increased diastolic pressure) can be result of aldosterone-induced sodium and water retention. This hypertension is often resistant of pharmacologic treatment. Fatigue, muscle cramps, and muscle weakness are presented due to hypokalemia. Diagnosing Conn's syndrome is quite simple. Clinical features can suggest the diagnosis but are not specific, but Conn's syndrome is suspected in presence of diastolic hypertension, low plasma renin and high plasma aldosterone not able to be suppressed by fluid challenge [6]. After this scenario the imagining methods and biochemistry examination are of great importance. Biochemistry examinations include renin and aldosterone blood level, potassium and sodium plasma concentration. Increased renin level can be faced in secondary hyperaldosteronism, whereas decreased renin is usually found in Conn's syndrome, associated with high aldosterone level. Aldosterone increases the effect of catecholamines, due to noradrenaline re-uptake blocking effect, and it predisposes to myocardial fibrosis resulting in arrhythmias and myocardial ischemia [7-9]. Hypokalemia is a constant finding, whereas hypernatremia can commonly be faced. Imagining examinations include ultrasound, angio-CT scan, and MRI. The diagnosis was confirmed by clinical features, and biochemistry findings, and supported by imagining examinations.

\section{Anesthetic considerations}

The anesthesiologist must deal with intraoperative hemodynamic changes and hypokalemia. It is well-known that hypokalemia and metabolic alkalosis may prolong the action of neuromuscular blocking agents, inducing bradycardia. Hypokalemia may be worsened by respiratory alkalosis (hyperventilation) and by sevoflurane-induced polyuria. The anesthesiologist must avoid hyperventilation and sevoflurane use as an inhalation anesthetic drug. The manipulation of adrenal gland during dissection and resection may lead to catecholamine release from the adrenal medulla with resultant hemodynamic fluctuations $[9,10]$. It is recently reported that Conn's syndrome can produce brisk and untreatable intraoperative hypertension [11]. The preoperative fluid volume status evaluation (the presence of orthostatism, increased heart rate, blood pressure, increased hematocrite, etc.) can detect hypovolemia. Hypovolemia is a rare condition and can be multifactorial including diuretics' use, anesthetic drugs' effects, positive pressure ventilation, laparoscopic approach, and the patient's position. Both hypervolemia and hypovolemia must be aggressively treated. Laparoscopic approach remains gold standard [12, 13]. It is generally accepted that laparoscopic approach may decrease postoperative cardiac and respiratory complications, less postoperative pain, and early ambulation [14]. Supplementation of hydrocortisone is another issue that anesthesiologist must deal with. Cortisol administration is helpful in perioperative hypoadrenocorticism or in chronic steroid administration [15]. Adrenal suppression induces hypotension, decreased cardiac output, hyponatremia, and hypoglycemia. It is mandatory to control cortisol level in preoperatively inadequate cortisol secretion patient, and cortisol supplementation as well. Etomidate must be avoided because it interferes with cortisol synthesis [16]. As a conclusion, Conn's syndrome presents different problems to the anesthesiologist. The anesthesiologist must deal with hypertension, hypervolemia, hypokalemia, and depending case by case with cortisol supplementation. A good cooperation between the anesthesiologist, endocrinologist, and surgeon is strongly recommended. The hottest problems are presented in Table 1.

\section{Cushing's Syndrome}

\section{General considerations}

Cushing's syndrome presents a typical complexity of clinical features, due to excessive circulating glucocorticoid level. The increased glucocorticoid level can be from either endogenous oversecretion or chronic treatment with glucocorticoids at higher doses. Approximately $70 \%$ of endogenous Cushing's syndrome are due to Cushing's disease (a primary pituitary ACTH-producing tumor), $15 \%$ results from ectopic production of $\mathrm{ACTH}$, and the last $15 \%$ are secondary to an adrenal tumor. It has been recently reported that Cushing's syndrome can rarely be caused by administration of oral steroids, injections of steroids, inhalers and unguents as well [17]. Patients under chronic steroid therapy (allergies, asthma, and arthritis) 
Table 2. Clinical Manifestation of Cushing's Syndrome [14]

\begin{tabular}{ll}
\hline Central obesity & Thin extremities \\
Supraclavicular fat & Proximal muscle weakness \\
Moon face & Hypertension \\
Buffalo hump & Hyperglycemia \\
Abdominal striae & Metabolic alkalosis \\
Skin thinning & Hypokalemia \\
Easy bruising & Menstrual irregularities \\
Osteopenia & Poor wound healing \\
\hline
\end{tabular}

may develop Cushing's syndrome. Several authors reported Cushing's syndrome associated with other tumors or clinical situations as pheochromocytoma [18, 19], sarcoidosis [20], pancreatic acinar cell carcinoma [21], pre-eclamptic findings [22], malignant gastrinoma [23], bronchial carcinoid lung tumor [24], pancreatic neuroendocrine tumor and Hippel-Lindau disease [25], and mesenteric neuroendocrine carcinoma [26].

The clinical scenario of Cushing's syndrome is a very characteristic one. Because of weight gain, the patients present the typical trio "moon facies", "buffalo hump", and central obesity. Skin thining and bruising associated with purple striae is another physical sign. Clinical manifestations also include proximal muscle weakness, fatigue, and spontaneous bone fractures due to osteopenia, sexual disorders (amenorrhea, infertility, menstrual irregularities, and decreased libido), hypertension secondary to water retention, hyperglycemia, metabolic alkalosis, and hypokalemia. The clinical features are summarized in Table 2 [14]. Cushing's disease resulting from pituitary adenoma can be manifested also with visual disturbances, head-ache, and elevated intracranial pressure.

Generally the patient suffering from Cushing's syndrome is evaluated by the endocrinologist and then referred to the surgical team. The diagnosis is usually confirmed by imagery and laboratory tests. Increased blood and urinary cortisol level, elevated urinary 17-hydroxycorticosteroids, and excessive plasma ACTH level, can suggest the diagnosis [27]. The next step is to differentiate Cushing's syndrome by Cushing's disease [28]. For this purpose, the so-called dexamethasone suppression test which can determine the origin of glucocorticoid hypersecretion (pituitary or adrenal origin) is often helpful. Pituitary adenoma is often associated with depression in cortisol and 17-hydroxycorticosteroid levels when a high dose of dexamethasone is administered because of negative feedback control, while adrenal tumors do not. Ultrasonography, angio$\mathrm{CT}$, and MRI can also be helpful in confirming the diagnosis. Ectopic glucocorticoid secreting tissues can be also detected using technetium 99 labeled octreotide scintigraphy examinations having receptors for somatostatin [24]. Arnaldi et al had recently described a detailed diagnosing algorithm [29].

\section{Anesthetic considerations}

Hypercortisolism can be preoperatively controlled with adrenal enzyme inhibitors, such as ketoconazole, metyrapone, mi- totane, or aminoglutethimide, given alone or in combination [30].

Adrenalectomy is also performed (open or laparoscopic) when a corticosteroid secretor adrenal hyperplasia is verified. Laparoscopic adrenalectomy remains gold standard. Cushing's syndrome is associated with longer hospitalizations, more frequent major complications, and higher advanced care requirements, especially for bilateral adrenalectomy [31]. Preoperative optimization includes the control of hypercortisolism, hypertension, hyperglycemia, hypokalemia, and prevention of perioperative hypercoagulative state. The patients are often hypertensive and hypervolemic, under chronic antihypertensive drugs as well. All the drugs must continue till the morning of surgery except the angiotensin converting enzyme inhibitors (ACEI) and angiotensin II receptor blockers (ARB) because of their exaggerated hypotensive effects after the anesthesia induction. Spironolactone will decrease the potassium loss [32]. Hyperglycemia is found to be associated with increased mortality, higher rates of infections, and longer hospitalization [33-35]. Oral agents are generally discontinued before surgery [26], substituted with insulin. The goal is to maintain blood glucose levels within 120 - $180 \mathrm{mg} / \mathrm{dL}$ during the perioperative period [36]. American Association of Clinical Endocrinologists (AACE) and ADA have recommended target values to $140-180 \mathrm{mg} / \mathrm{dL}$ for ICU and $100-180 \mathrm{mg} / \mathrm{dL}$ as a target for the diabetic patients in medical and surgical wards [36]. The prevention of perioperative venous thromboembolism and $\mathrm{PE}$ can be realized using LMWH, lower-extremity compression devices [37], and early postoperative mobilization.

The anesthetic care consists in a detailed anesthetic plan, careful positioning and taping, and premedication technique. The anesthesiologist must take care during positioning and taping the patient, in order to prevent bone fractures and skin damages. Deep sedation must be avoided because of hypoxia risk and difficult airways. These patients are in increased risk for gastric aspiration, which can be prevented using metoclopramide, ranitidine, and sodium citrate. The detailed anesthetic plan includes possible difficult airway management, rapid induction of anesthesia, standard and/or invasive monitoring, large bore veins, central lines, and/or epidural catheter placement. Airway management may be difficult because of central obesity and proximal muscle weakness. The mask ventilation and endotracheal intubation may be difficult. Restrictive respiratory failure can be induced by obesity, associated with reduced functional residual capacity (FRC). Hypoventilation, 
Table 3. Perioperative Problems of Cushing's syndrome Anesthetic Management

\begin{tabular}{|c|c|}
\hline Cushing's syndrome & Treatment \\
\hline \multicolumn{2}{|l|}{ Preoperative period } \\
\hline Cortisol inhibition & Adrenal enzyme inhibitors \\
\hline Hypertension & Continue chronic therapy except ACEI and ARB \\
\hline Hyperglycemia & Stop oral therapy and begin insulin regimen \\
\hline Hypokalemia & Begin spironolactone and supplement potassium \\
\hline Perioperative hypercoagulative state & LMWH, lower-extremity compression devices, and early postoperative mobilization \\
\hline \multicolumn{2}{|l|}{ Intraoperative period } \\
\hline Detailed anesthetic plan & General endotracheal anesthesia \pm epidural \\
\hline Positioning and taping & Careful and gentle positioning, avoid fractures \\
\hline Premedication technique & Avoid deep sedation \\
\hline Gastric aspiration risk & Drugs, rapid induction, Sellick maneuver \\
\hline Airway management & Careful preoxygenation, ensure correct intubation \\
\hline Venous access & Large bore peripherial and central venous catheters \\
\hline Invasive monitoring & Radial artery cannulation, Swan-Ganz if required \\
\hline Biochemistry tests & Close monitoring of glycemia, electrolytes, and $\mathrm{pH}$ \\
\hline Postextubation respiratory failure & Awake extubation, close monitoring \\
\hline \multicolumn{2}{|l|}{ Postoperative period } \\
\hline Acute pain therapy & Aggressive treatment, systemic/epidural opioid \\
\hline Biochemistry tests & Close monitoring of glycemia, electrolytes, cortisol and $\mathrm{pH}$ \\
\hline Postoperative respiratory failure & Respiratory exercises, pain killers, mobilization \\
\hline Venous thrombotic episodes & LMWH, early mobilization \\
\hline
\end{tabular}

atelectasis, and hypoxia may be the consequences of reduced FRC. These respiratory complications can be prevented by suitable preoxygenation, and appropriated extubation. Standard monitoring includes non-invasive blood pressure, temperature, end-tidal carbon dioxide, pulse oximetry, and electrocardiography. Invasive monitoring includes invasive blood pressure monitoring through an arterial catheter cannulation, and if necessary Swan-Ganz pulmonary artery catheter [14]. Large bore vein catheters, and central vein accesses are mandatory, in order to facilitate the fluids and drugs administration. The use of epidural anesthesia seems to be helpful [38] in controlling pain and reducing cardiac and pulmonary complications. Hydrocortisone succinate must be available in operating room in order to prevent a possible glucocorticoid deficiency. Aggressive pain treatment, early mobilization, hypertension and hyperglycemia control, and finally cortisol level monitoring are the essential postoperative problems that the anesthesiologist must deal with. As a conclusion, the controls of perioperative hypertension, hyperglycemia, hypokalemia, and cortisol blood level are hallmarks of the anesthesiologist's role treating the Cushing patient. Table 3 summarizes all perioperative events.

\section{Pheochromocytoma}

\section{General considerations}

Pheochromocytoma presents the biggest challenge to the anesthesiologist compared with the other hormone secretion adrenal tumors. This disease is characterized by excess of catecholamine secretion inducing a sympathetic storm mostly presented by severe hypertension and arrhythmias. Pheochro-

Table 4. Sensitivity and Specificity of Pheochromocytoma Diagnosing Tests [10, 41]

\begin{tabular}{lll}
\hline Test/symptom & Sensitivity (\%) & Specificity (\%) \\
\hline Vanillylmandelic acid & 81 & 97 \\
Catecholamine excretion & 82 & 95 \\
Metanephrine excretion & 83 & 95 \\
Abdominal CT scan & 92 & 80 \\
Paroxysmal hypertension, headache, sweating, tachycardia & 90 & 95 \\
\hline
\end{tabular}


Table 5. The Differences Between Phenoxybenzamine and Doxazosin

\begin{tabular}{ll}
\hline Phenoxybenzamine & Doxazosin \\
\hline Non selective $\alpha 1$-adrenergic blocker & Selective $\alpha 1$-adrenergic blocker \\
Central signs present & No central signs (headache, nasal stuffiness) \\
$\beta$-blocker always necessary & $\beta$-blocker not always necessary \\
\hline Prolonged and severe hypotension after adrenalectomy & No significant hypotension after adrenalectomy \\
Postural hypotension & No postural hypotension \\
Residual adrenergic blockade & No residual adrenergic blockade \\
\hline
\end{tabular}

mocytoma can be adrenal or extrarenal (paraganglia), and can excessively secrete epinephrine, norepinephrine, and rarely dopamine. This tumor can also be associated with multiple endocrine neoplasia [39]. Ten percent of pheochromocytomas may be maligns, and $10 \%$ may be bilateral. It has been recently reported that $25-50 \%$ of deaths may occur during anesthesia induction [40].

The first signs suggesting pheochromocytoma are excessive sweating, headache, hypertension, arrhythmias, and palpitations. Imaging tools such as MRI and CT scan help find an adrenal tumor. The most important step in diagnosing pheochromocytoma is laboratory examinations that are summarized in Table 4.

\section{Anesthetic considerations}

Anesthetic management of pheochromocytoma consists of sev- eral points: perioperative hemodynamic control, intraoperative control, and postoperative care. Generally perioperative hemodynamic control can be performed by anesthesiologist and endocrinologist. The mainstay therapy consists of combination of an $\alpha$-adrenergic blocker and $\beta$-blocking agent. Short-acting, selective, competitive $\alpha 1$-adrenergic receptors blockers (doxazosin 2 - 6 mg daily) have been used in pheochromocytoma's patients to prepare them for surgery. A potential advantage of competitive, selective $\alpha 1$-blockade is that, once the tumor has been resected and excess catecholamine release eliminated, $\alpha$-adrenergic receptors return quickly to normal function, leading to less hypotension [41-43]. Phenoxybenzamine because of more severe and prolonged hypotension after the adrenal gland removal is usually stopped 24 - $48 \mathrm{~h}$ before surgery. Table 5 summarizes the differences between selective and nonselective $\alpha 1$-adrenergic receptors blockers [44].

Tachycardia must be treated using $\beta$-adrenergic blockers after the $\alpha$-adrenergic blockade is effectively instituted.

Table 6. Vasoactive Drugs Used During Pheochromocytoma's Resection

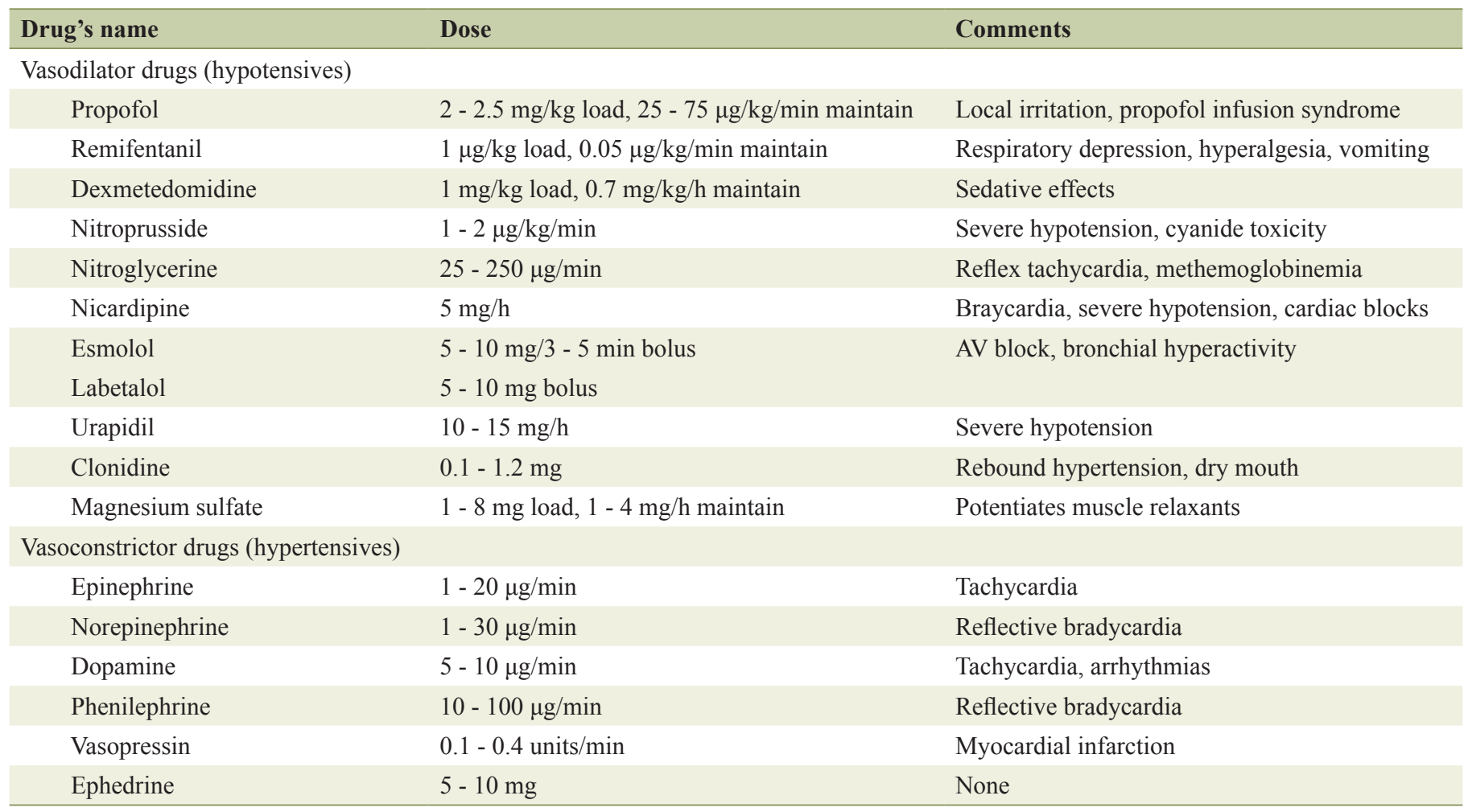


Other strategies include calcium blockers [45], clonidine, and magnesium sulfate [46]. An adequate adrenergic blockade is considered when the patient fulfills the following criteria: no hypertension (blood pressure over 160/90) during the last 24 $\mathrm{h}$, no orthostatic hypotension, no change in ST-T wave, and no more than one premature ventricular contraction in $5 \mathrm{~min}$.

Intraoperatively several points are to be considered. Standard and invasive monitoring is mandatory. Radial arterial catheter insertion must be performed before induction of anesthesia using local anesthetics such as EMLA. Large bore peripheral and central venous catheters are usually required to administer large amount of liquids and vasoactive drugs as necessary. The preoperative sedation must be judged case by case, but generally deep sedation ensuring airway management is strongly recommended. All drugs (pancuronium, ketamine, halothane, and desflurane) that can simulate the sympathetic system inducing hypertension and tachycardia are to be avoided. The anesthesia induction and endotracheal intubation must be smooth in order to avoid the increasing of the sympathetic tone. For this purpose the anesthesiologist can use different drugs [47-49] such as vasodilators (nitropruside, nitroglycerine, urapidil, and nicardipine), short-acting $\beta$-blocking drugs (esmolol), magnesium sulfate, and anesthetic drugs (remifentanil and propofol). Total intravenous anesthesia (combination of propofol and remifentanil as a continuous infusion) and dexmedetomidine [50] are modern options providing an adequate depth of anesthesia and blunting the sympathetic response during intubation and adrenal gland surgical manipulation. After the adrenal gland removal, a severe hypotension may occur. This hypotension is due to nonselective $\alpha$-adrenergic blockers, deep anesthesia, and reduced blood volume (bleeding, diuretics, and preoperative uncorrected hypovolemia). Several vasopressors/inotropes can be used such as epinephrine, norepinephrine, dopamine, and vasopresine. Table 6 describes all vasoactive drugs used to control the hemodynamic during intraoperative period.

As a conclusion, preoperative hormonal evaluation, preoperative hemodynamic control, smooth and gentle induction of anesthesia, modern anesthetic drugs, and strong intraoperative collaboration with surgical team, are the most important steps that can guarantee the successful management of pheochromocytoma's resection.

\section{References}

1. Williams, Dluhy RG. Disorders of the Adrenal Cortex. In: Fauci A, Braunwald E, Kasper D, Hauser S, Longo D, Jameson J, Loscalzo J, ed. Harrison's Principles of Internal Medicine. 17th Ed. McGraw Hill Professional Publishing, 2008:2259-2260.

2. Michael FR, Fleisher LA. Anesthetic Implications of Concurrent Diseases. In: Miller RD, ed. Miller's Anesthesia. 7th ed. Philadelphia: Churchill Livingstone, 2009:10671150.

3. Calhoun DA. Aldosteronism and hypertension. Clin J Am Soc Nephrol. 2006;1(5):1039-1045.

4. Wheeler MH, Harris DA. Diagnosis and management of primary aldosteronism. World J Surg. 2003;27(6):627631.

5. Mattsson C, Young WF, Jr. Primary aldosteronism: diagnostic and treatment strategies. Nat Clin Pract Nephrol. 2006;2(4):198-208; quiz, $191 \mathrm{p}$ following 230.

6. Quinkler M, Reincke M. [Modern pharmacological aspects of hyperaldosteronism therapy]. Internist (Berl). 2006;47(9):953-959.

7. Funder JW. Aldosterone, salt and cardiac fibrosis. Clin Exp Hypertens. 1997;19(5-6):885-899.

8. Zannad F. Aldosterone and heart failure. Eur Heart J. 1995;16(Suppl N):98-102.

9. Winship SM, Winstanley JH, Hunter JM. Anaesthesia for Conn's syndrome. Anaesthesia. 1999;54(6):569-574.

10. Domi R, Sula H. Pheochromocytoma, the challenge to anesthesiologist. J Endocrinol Metab. 2011;1(3):97-100.

11. Gockel I, Heintz A, Kentner R, Werner C, Junginger T. Changing pattern of the intraoperative blood pressure during endoscopic adrenalectomy in patients with Conn's syndrome. Surg Endosc. 2005;19(11):1491-1497.

12. Lertakyamanee N, Somprakit P, Buranakijaroen P, Lertakyamanee J, Nimmanwudipong T, Sriussadaporn S. Anesthesia and laparoscopic adrenalectomy for primary aldosteronism. J Med Assoc Thai. 2001;84(6):798-803.

13. Edwin B, Raeder I, Trondsen E, Kaaresen R, Buanes T. Outpatient laparoscopic adrenalectomy in patients with Conn's syndrome. Surg Endosc. 2001;15(6):589-591.

14. Domi R. Cushing' surgery: Role of the anesthesiologist. Indian J Endocr Metab. 2011;15:322-328.

15. Shaikh S, Verna H, Yadav N, Jauhari M, Bullangowda J. Application of steroid in clinical practice: a review. ISRN Anesthesiology, Volume 2012, Art ID 985495.

16. Absalom A, Pledger D, Kong A. Adrenocortical function in critically ill patients $24 \mathrm{~h}$ after a single dose of etomidate. Anaesthesia. 1999;54(9):861-867.

17. Semiz S, Balci YI, Ergin S, Candemir M, Polat A. Two cases of Cushing's syndrome due to overuse of topical steroid in the diaper area. Pediatr Dermatol. 2008;25(5):544547.

18. Bayraktar F, Kebapcilar L, Kocdor MA, Asa SL, Yesil $\mathrm{S}$, Canda S, Demir T, et al. Cushing's syndrome due to ectopic CRH secretion by adrenal pheochromocytoma accompanied by renal infarction. Exp Clin Endocrinol Diabetes. 2006;114(8):444-447.

19. Kumar M, Kumar V, Talukdar B, Mohta A, Khurana N. Cushing syndrome in an infant due to cortisol secreting adrenal pheochromocytoma: a rare association. J Pediatr Endocrinol Metab. 2010;23(6):621-625.

20. Schaefer S, Meyer S, Brueck CC, Weber M, Luedecke D, Wagner HJ, Kann PH. Sarcoidosis following Cushing's syndrome: A report of two cases and review of the literature. Exp Clin Endocrinol Diabetes. 2010;118(3):147150.

21. Illyes G, Luczay A, Benyo G, Kalman A, Borka K, Koves K, Racz K, et al. Cushing's syndrome in a child with pancreatic acinar cell carcinoma. Endocr Pathol. 2007;18(2):95-102.

22. Delibasi T, Ustun I, Aydin Y, Berker D, Erol HK, Gul K, 
Unal M, et al. Early severe pre-eclamptic findings in a patient with Cushing's syndrome. Gynecol Endocrinol. 2006;22(12):710-712.

23. Park SY, Rhee Y, Youn JC, Park YN, Lee S, Kim DM, Song SY, et al. Ectopic Cushing's syndrome due to concurrent corticotropin-releasing hormone $(\mathrm{CRH})$ and adrenocorticotropic hormone (ACTH) secreted by malignant gastrinoma. Exp Clin Endocrinol Diabetes. 2007;115(1):13-16.

24. Esfahani AF, Chavoshi M, Noorani MH, Saghari M, Eftekhari M, Beiki D, Fallahi B, et al. Successful application of technetium-99m-labeled octreotide acetate scintigraphy in the detection of ectopic adrenocorticotropin-producing bronchial carcinoid lung tumor: a case report. J Med Case Rep. 2010;4:323.

25. Benitez Velazco A, Pacheco Capote C, Latre Romero JM. [Ectopic Cushing's syndrome caused by a functioning pancreatic neuroendocrine tumour in a patient with von Hippel-Lindau disease]. Rev Esp Med Nucl. 2008;27(1):29-33.

26. Fasshauer M, Lincke T, Witzigmann H, Kluge R, Tannapfel A, Moche M, Buchfelder M, et al. Ectopic Cushing' syndrome caused by a neuroendocrine carcinoma of the mesentery. BMC Cancer. 2006;6:108.

27. Newell-Price J, Bertagna X, Grossman AB, Nieman LK. Cushing's syndrome. Lancet. 2006;367(9522):16051617.

28. Vaughan ED, Jr. Diseases of the adrenal gland. Med Clin North Am. 2004;88(2):443-466.

29. Arnaldi G, Angeli A, Atkinson AB, Bertagna X, Cavagnini F, Chrousos GP, Fava GA, et al. Diagnosis and complications of Cushing's syndrome: a consensus statement. J Clin Endocrinol Metab. 2003;88(12):5593-5602.

30. Diez JJ, Iglesias P. Pharmacological therapy of Cushing's syndrome: drugs and indications. Mini Rev Med Chem. 2007;7(5):467-480.

31. Kissane NA, Cendan JC. Patients with Cushing's syndrome are care-intensive even in the era of laparoscopic adrenalectomy. Am Surg. 2009;75(4):279-283.

32. Ural AU, Avcu F, Cetin T, Beyan C, Kaptan K, Nazaroglu NK, Yalcin A. Spironolactone: is it a novel drug for the prevention of amphotericin B-related hypokalemia in cancer patients? Eur J Clin Pharmacol. 2002;57(11):771773.

33. Bochicchio GV, Sung J, Joshi M, Bochicchio K, Johnson SB, Meyer W, Scalea TM. Persistent hyperglycemia is predictive of outcome in critically ill trauma patients. J Trauma. 2005;58(5):921-924.

34. Pomposelli JJ, Baxter JK, 3rd, Babineau TJ, Pomfret EA, Driscoll DF, Forse RA, Bistrian BR. Early postoperative glucose control predicts nosocomial infection rate in diabetic patients. JPEN J Parenter Enteral Nutr. 1998;22(2):77-81.

35. Carson JL, Scholz PM, Chen AY, Peterson ED, Gold J, Schneider SH. Diabetes mellitus increases short-term mortality and morbidity in patients undergoing coronary artery bypass graft surgery. J Am Coll Cardiol. 2002;40(3):418-423.
36. Moghissi ES, Korytkowski MT, DiNardo M, Einhorn D, Hellman R, Hirsch IB, Inzucchi SE, et al. American Association of Clinical Endocrinologists and American Diabetes Association consensus statement on inpatient glycemic control. Endocr Pract. 2009;15(4):353-369.

37. Geerts WH, Bergqvist D, Pineo GF, Heit JA, Samama CM, Lassen MR, Colwell CW. Prevention of venous thromboembolism: American College of Chest Physicians Evidence-Based Clinical Practice Guidelines (8th Edition). Chest. 2008;133(6 Suppl):381S-453S.

38. Svircevic V, van Dijk D, Nierich AP, Passier MP, Kalkman CJ, van der Heijden GJ, Bax L. Meta-analysis of thoracic epidural anesthesia versus general anesthesia for cardiac surgery. Anesthesiology. 2011;114(2):271-282.

39. Huynh TT, Pacak K, Brouwers FM, Abu-Asab MS, Worrell RA, Walther MM, Elkahloun AG, et al. Different expression of catecholamine transporters in phaeochromocytomas from patients with von Hippel-Lindau syndrome and multiple endocrine neoplasia type 2. Eur J Endocrinol. 2005;153(4):551-563.

40. Del Pizzo JJ, Schiff JD, Vaughan ED. Laparoscopic adrenalectomy for pheochromocytoma. Curr Urol Rep. 2005;6(1):78-85.

41. Pauker SG, Kopelman RI. Interpreting hoofbeats: can Bayes help clear the haze? $N$ Engl J Med. 1992;327(14):1009-1013.

42. Prys-Roberts C, Farndon JR. Efficacy and safety of doxazosin for perioperative management of patients with pheochromocytoma. World J Surg. 2002;26(8):1037-1042.

43. Kinney MA, Narr BJ, Warner MA. Perioperative management of pheochromocytoma. J Cardiothorac Vasc Anesth. 2002;16(3):359-369.

44. Domi R, Laho H. Management of pheochromocytoma: old ideas and new drugs. Niger J Clin Pract. 2012;15(3):253257.

45. Lebuffe G, Dosseh ED, Tek G, Tytgat H, Moreno S, Tavernier B, Vallet B, et al. The effect of calcium channel blockers on outcome following the surgical treatment of phaeochromocytomas and paragangliomas. Anaesthesia. 2005;60(5):439-444.

46. James MF, Cronje L. Pheochromocytoma crisis: the use of magnesium sulfate. Anesth Analg. 2004;99(3):680686 , table of contents.

47. Dooley M, Goa KL. Urapidil. A reappraisal of its use in the management of hypertension. Drugs. 1998;56(5):929955.

48. Zakowski M, Kaufman B, Berguson P, Tissot M, Yarmush L, Turndorf H. Esmolol use during resection of pheochromocytoma: report of three cases. Anesthesiology. 1989;70(5):875-877.

49. Grant F. Anesthetic considerations in the multiple endocrine neoplasia syndromes. Curr Opin Anaesthesiol. 2005;18(3):345-352.

50. Bryskin R, Weldon BC. Dexmedetomidine and magnesium sulfate in the perioperative management of a child undergoing laparoscopic resection of bilateral pheochromocytomas. J Clin Anesth. 2010;22(2):126-129. 